\title{
DETERMINISM AND THE POSSIBILITY OF MORALITY
}

\author{
Dr. Zahoor H. Baber
}

\begin{abstract}
The possibility of morality in a causally determined physical world engages philosophers in a serious debate. Many philosophers think that morality is not possible in a world where everything, including human actions, is determined by antecedent causal conditions. However, attempts to reconcile these apparently contradictory views have come forth. What emerges through the debate is that even if all human actions are causally determined, moral commitments are irreplaceable. Therefore, it is argued that causal determination of our thoughts and actions does not change the truth of morality. However, a morality involving determinism seems to rely heavily on the causal efficacy of moral judgments rather than the possibility of a free action. The deterministic morality focuses on human motivation as a cause and ignores the possibility of free choice. Moreover, a deterministic morality is unable to account for the freedom of the will. However, in serious climate of opinion, morality essentially involves moral responsibility based on a free choice and action. Thus, philosophical attempts to reconcile determinism and morality under the assumption of irreplaceable human interpersonal attitudes seem not so convincing. This paper brings forth the philosophical arguments involved; centralizing on the contention that morality cannot be subsumed under determinism.
\end{abstract}

Key Words: Causality, Morality, Determinism, Freedom, Responsibility, Choice, Free Will

\section{INTRODUCTION}

Determinism is the thesis that all events in nature are caused by prior events in nature such that an uncaused event is impossible, including the mental and physical events involving human actions. Though determinism does not deny conscious purposes, yet it claims that they are caused by prior physical or mental events that in turn are caused by physical events external to consciousness. In general, all physical and mental occurrences are determined by prior causes such that in principle every occurrence is predictable by the knowledge of the antecedent causal conditions that determine the consequent state of affairs of the physical world. This raises the question how morality is possible that relies on freedom of choice and action entailing moral responsibility in the human world. If determinism is true for all human behavior whether moral, immoral, normal, or abnormal, what are the grounds of distinctions between these types of attitudes and responses amongst persons? Causal determination of all behavior implies that no person could have acted or behaved otherwise than how he actually did, and will do likewise again given the same antecedent causal conditions.

This also raises the question why we react differently towards the normal and abnormal persons. Are there some reasons other than determinism for the suspension of our moral attitudes towards the abnormal person? P.F. Strawson 
thinks that the problem involves our attitudes towards the normal and abnormal behavior. In case of the normal behavior our 'reactive attitudes' towards persons is not suspended. In case of the abnormal behavior we think that the person is unable to choose, therefore, we might suspend our reactive attitudes towards him because he cannot behave otherwise and needs a treatment rather than a moral judgment. Strawson seems to suggest that we exclude the abnormal from the moral community not merely because his abnormal behavior is causally determined but also because we know that he is under compulsion of certain unconscious causes beyond his control. In other words, Strawson thinks that we adopt an 'objective attitude' towards the abnormal persons rather than a human subjective attitude or an 'interpersonal attitude'. We expel the abnormal by taking him as an object of treatment rather than subject of normal human response. However, this implies that Strawson presupposes that the normal has a conscious control over how he behaves or acts. But if determinism is true, no one can act or behave otherwise; then how he actually does? Thus our supposition of having a conscious control over our attitudes seems groundless. This means we are face to face with a dilemma that if determinism is true, our supposition of having a conscious control over our actions is an ignorance of the actual causes that determines them. And thus we are stuck with the question as to what distinguishes the normal from the abnormal, and what are the grounds of morality in a deterministic world.

However at this point Strawson thinks otherwise. He claims that to be human and to be a part of moral community are identical. Even if determinism is true, normal human response cannot be transformed into an objective attitude towards all. On this point Strawson sees that determinism is irrelevant as a problem for deciding whether morality is possible or not. This is so because Strawson thinks that even if determinism is true, we cannot give up our moral and interpersonal attitudes. We will continue to behave towards each other as normal human person rather than objects. Therefore, Strawson thinks that determinism poses no threat against justification of morality.

However, this seems to be an oversight on part of Strawson. Though he could be right that morality based on interpersonal attitude is irreplaceable despite determinism, yet the problem of abnormality must be addressed by reasons that involve the distinction. The distinction cannot be merely based on deviation from the normal. It is presupposed that the abnormal cannot change by willing to be normal. He is under uncontrollable compulsion. But if the normal is as much determined as the abnormal in being what both are, Strawsonian irreplaceability of normal interpersonal attitudes does not prove that determinism is irrelevant. Rather, it seems to bypass the question of having a free will that is impossible in a deterministic world. Thus in what follows, I will expound on Strawsonian stance further to show where it stands in the whole controversy of freedom and determinism. 


\section{CONSCIOUS CONTROL AND FREEDOM}

The problem of conscious control is the crux of the whole issue arising out of the possibility of morality in deterministic world. Strawson seems to think that the pessimistic philosophers who believe in a contra-causal freedom wrongly hold that determinism is a threat to the possibility of moral freedom. The pessimists wrongly contend that if determinism is true and if all human behavior is caused, moral freedom is not possible. They ironically infer that if all human behavior is caused, it is caused in the same way as the abnormal behavior that no one can change by rational considerations. In other words, Strawson thinks determinism does not imply that no one can act otherwise even if the antecedent causal conditions determine how he acts.

For Strawson, it seems that the causal determination of behavior does not imply that a person cannot act with a conscious and rational purpose. Determination does not deny conscious control; it only implies that it is caused. Though what we call as normal is as much as caused as the abnormal, the distinction rests on our "reactive attitudes" towards them rather than what determinism implies. Therefore, for Strawson determinism is irrelevant and the pessimist philosophers need not worry.

On the other hand, what Strawson terms as the 'optimist' thinks that determinism does not imply all behavior to be caused in the same way as the abnormal behavior is caused. For the optimist deterministic morality is the only possible morality since moral judgments play a causal role in determining the future actions.

Given this, the Strawsonian reconciliation between the optimists and the pessimists rests on his fundamental contention that even if determinism is true, we as humans, cannot give up our usual normal 'interpersonal attitudes' towards each other. $\mathrm{He}$ thinks that this fact shows that determinism is irrelevant here since we remain what we are, persons, having interpersonal relations irrespective of whether our behavior is caused by factors beyond our consciousness. From this Strawson concludes that the conflict between pessimists libertarian and optimist determinist can be resolved. The irrelevance of determinism means to Strawson that our moral stance has other reasons than what the thesis of determinism implies. It seems that for Strawson morality is a human commitment rather than a matter of causal or contra-causal freedom. Whether a behavior is caused or uncaused, we remain persons committed to each other as persons.

However, if we follow Strawson that the conflict between the pessimists and optimists is misplaced, his solution faces the same difficulty that optimists have to face. This lies in what Richard Double points out as the 'objective standard' or extra- linguistic reality of free choice in contrast to the Strawsonian version of morality based on human commitment. Richard Double States:

The standard free will theories...presuppose that when we talk about freedom and moral responsibility, we are making statements about the nature of extralinguistic reality. The...determinists deny what the...libertarians assert, but even the denial is a claim about the nature of non-linguistic, non-subjective reality. All sides agree that free will dispute is a debate over whether our choices are free enough to support genuine moral responsibility. All sides 
agree that the question is whether our choices meet the objective standard and is not simply a matter of how we 'feel about' our choices.

Given this claim about the objective standard of morality required by the opponents, Strawson's view of morality becomes subjective. His strategy for the reconciliation between optimists and pessimists is based on his own assumption that moral responsibility is a matter of how man feels about humanity. This assumption and what it implies seem to have led Strawson in forwarding an apparently pragmatic view of morality. Consequently, the subjective morality incorporates optimism in a deterministic world; where all human behavior is causally necessitated but still moral. We hold each other responsible not because we are actually free but because we are human and cannot do otherwise. Against this, Peter Van Inwagen claims that moral responsibility depends on free will. He states:

[If] moral responsibility exists, then someone is morally responsible for something he has done or has left undone, to be morally responsible...is to have free will. Therefore, if no one has free will, moral responsibility does not exist. $^{2}$

Following this it becomes clear that the possibility of morality in the deterministic world carries a hope of the optimist that morality is possible without having a free will. While the pessimist clings to the view that without free will morality is not possible because moral responsibility presupposes having a free will. Attempts to reconcile optimistic and pessimistic views about morality and determinism override the question of having a free will.

\section{INCOHERENCE OF PESSIMISTS AND OPTIMISTS}

The pessimists are libertarians worrying that if determinism is true, our whole moral conception is false. Contrarily, the optimists are determinists who hold that determinism is true, but its truth does not imply erosion of moral responsibility. The pessimists think that moral responsibility is impossible without a possibility to act otherwise. That means there must be a possibility of freedom or free will, in a nondeterministic sense. The whole issue of morality, converges on the question of a freedom that somehow cannot be brought within the paradigm of natural causality. But the optimists or determinists deny any such possibility. They conceded that the causal nexus of nature is complete in the sense that human choices and actions are not exception. There cannot be any un-caused freedom that the pessimists require.

The conflict between pessimist and optimist on the question of morality is usually conceived in above mentioned terms. But Strawson thinks that they misconstrue the facts as we know them in our interpersonal and objective attitudes. To Strawson, the optimist is clear of his own conception of morality that is deterministic. Moral appraisals play a causal role in changing the un-approvable behavior as well as enhancing the approvable one. The causal efficacy of reward and punishment is the central aspect of the optimist's morality. He does not require a contra-causal freedom for the conception of morality. The social utility of morality is the only

\footnotetext{
${ }^{1}$ Richard Double, The Non-Reality of Free Will, (Oxford: Oxford University Press, 1991) 135.

${ }^{2}$ Peter Van Inwagen, An Essay on Free Will,(Oxford: Oxford University Press, 1983) 162.
} 
reason that the optimist finds justified in continuing to stick to the same in social practices. For this, the optimist invokes the thesis of determinism.

The optimist argues against the pessimist that without the causal efficacy of moral practices, punishment, for instance, has no justification. This utilitarian approach involves the claim that morality presupposes determinism and requires it. As John Stuart Mill states:

The question deemed to be so puzzling is how punishment can be justified if men's actions are determined by motives, among which motives punishment is one. A more difficult question would be how it can be justified if they are not so determined. Punishment proceeds on the assumption that the will is governed by motives. If punishment had no power of acting on the will, it would be illegitimate, however natural might be the inclination to inflict it. Just so far as the will is supposed free, that is capable of acting against motives, punishment is disappointed of its object, and deprived of its justification. $^{3}$

Nevertheless, Mill's line of thinking, though apparently softer in its utilitarian sense, must be seen as leading back to fatalistic world view of Baron d' Holbach. To Holbach, if motives govern all human actions and will, they are not isolated mental phenomena within an overall causal nexus of nature.

Man's life is a line that nature commands him to describe upon the surface of the earth without his ever being able to severe from it, even for an instant..he is unceasingly modified by causes, whether visible or concealed, over which he has no control, which necessarily regulate his mode of existence.. and determine his manner of acting. ${ }^{4}$

If this is true then it is not difficult to see why any thoroughgoing determinism entails fatalistic morality, including that of Holbach.

Man congregates himself in society, modified each his follow; becomes either virtuous or wicked; either contributes to his mutual happiness, or reciprocates misery; either loves his neighbor, or hates his companion necessarily, according to the manner in which one acts upon another. From whence it may be seen, that the same necessity which regulates the physical also regulates the moral world, in which everything is in consequence submitted to fatality. ${ }^{5}$

Thus, the fatalist morality dissolves optimist's hope of retaining a non-fatalist morality. But the Strawsonian pessimist thinks that the optimist's conception of morality is greatly repulsive in the sense that believing in it entails adopting Strawsonian objective attitude towards all. However, the pessimist does not necessarily concede that determinism implies all normal behavior identical to the abnormal one. Rather, most of the pessimists, only consider that in a deterministic world there is no possibility of choosing or acting otherwise than what one actually

\footnotetext{
${ }^{3}$ John Stuart Mill, “An Examination of Sir William Hamilton's Philosophy”, in Classic Philosophical Questions, ed, J.A Gould, (Prentice Hall, 2006, first published 1971), 74.

${ }^{4}$ Paul Henry Thiry, Baron d' Holbach, "Determinism", in Freedom: Its History, Nature and Varieties, ed. R.E. Dewey and J.A Gould, (New York, Macmillan, 1970), 110.

${ }^{5}$ Ibid., 117.
} 
does. If all choices are caused in the same sense in which any natural process or event is caused, one could not have chosen otherwise than what one in fact chose.

What sense of choice is left when one is caused to choose A than B? For, the choosing of $\mathrm{A}$ is as much determined by antecedent conditions as the choosing of $\mathrm{B}$. In a more inclusive sense, there is no choice here at all. Rather, there are causes which determine the mental event of following a particular action A, while in our mind we may continue to believe that we could have chosen B instead. But this belief, given the antecedent causal determination beyond consciousness, remains merely a belief without ever being true in an objective sense. It is clear that if rational choices and decisions make sense, they do so because we take them in a non- causal sense. MacIntyre states:

Suppose that the determinist is able to supply a complete explanation of my behavior in causal terms. Suppose also that my behavior is rational, that whatever strong reasons are adduced for acting in a certain way I act in that way, that I am infinitely flexible and resourceful in meeting new contingencies. Then no test will be available to decide whether I act as I do because it is the rational way to act or because it is the way in which my deeds are causally determined. For on either supposition I will do the same thing. To try and include my reasonableness in a story about causal factors is to try to produce a story about my behavior sufficiently comprehensive to include everything. This means that whereas the contention that my behavior is determined by causal factors is normally taken to mean'determined by causal factors as contrasted with rational appreciation, etc.' here causal factors have nothing to be contrasted with and hence the expression determined by causal factors has been evacuated of its customary meaning. ${ }^{6}$

Thus the Strawsonian pessimist, or for that matter a libertarian, seems justified in rejecting a determinist morality, despite the determinist's concession of possibility and efficacy of choices. The determinist or optimist is using the libertarian vocabulary of choices to hide the actual meaning of a caused mental event. He should not be talking or using the word choice at all. He should be claiming that a mental event causes a physical event, the former itself being caused by other antecedent mental events, leading back to the causal chain of events outside one's consciousness'. This shows clearly that there is no place of real choices in a determinist morality. Therefore, the pessimist is right in his pessimism that if determinism is true then moral responsibility is impossible.

Weatherford thinks that Strawson's view about irrelevance of determinism is right, but his conclusion that pessimists are wrong is not a correct view. Weatherford states:

Strawson argues that merely discovering determinism to be true would not force us all to abandon the 'participant attitude' and adopt the 'objective attitude' towards each other, and on this I believe he is quite right, eloquent, even profound. But the moral that some have drawn from this that the incompatibilists are wrong is I think not quite right. ${ }^{7}$

\footnotetext{
${ }^{6}$ A.C. MacIntyre, 'Determinism', in Free will and Determinism, ed. Bernard Berofsky, op cit. pp. 254.

${ }^{7}$ Roy Weatherford, Implications of Determinism, Op. cit. 89
} 
Weatherford thinks that the pessimist incompatibilists concede that moral responsibility will have to be drastically reformulated in a deterministic world. This however, would lead us to deny moral responsibility in the proper sense. According to Weatherford,

Strawson is right to disparage the 'panicky metaphysics' of the libertarian and to show that their cure is worse than the disease. But the metaphysics is the essence of the moral theory and it is here that therapy is needed. For the moral of Strawson's story is that we will not give up our personal and ethical responses to each other even if determinism is true and therefore we will have to revise our views on moral responsibility. But the incompatibilist is right in saying that if detrminism is true, then we will have to revise our views on moral responsibility or admit that no one is morally responsible because the two are incompatible as they stand and this I think is where the incompatibilists are right and the compatibilists wrong. ${ }^{8}$

Nevertheless, Strawson claims that the pessimists and optimists deny each other because of their respective misconceptions. Strawson states:

Optimists and pessimists misconstrue the facts in very different styles. But in a profound sense there is something in common to their misunderstanding. Both seek, in different ways to over intellectualize the facts. Inside the general structure or web of human attitudes and feelings of which I have been speaking there is endless room for modification, redirection, criticism, and justification. But questions of justification are internal to the structure or relate to modifications internal to it. The existence of the general framework of attitudes itself is something we are given with the fact of human society. As a whole, it neither calls for, nor permits an external justification. Pessimists and optimists alike show themselves, in different ways, unable to accept this. ${ }^{9}$

Here it seems that Strawson is taking too much for granted about human attitudes. After all, despite the general framework of attitudes, what distinguishes humans from other creatures and objects? It would not be sufficient to respond to this by saying that humans have their own set of attitudes different from animals and plants. What difference is that? If it is argued that the set of attitudes is itself a given fact and it needs no external justification, it means no line can be drawn. For, at times, or most of the time, man behaves like an animal. Still at other times he does not. What justification can be offered for the existence of those attitudes which are not purely animal attitudes? In general, what makes us human rather than animals? It would not be sufficiently convincing to respond that humans and animals have different sets of attitudes with no clear distinction.

If a line can be drawn here, it is the fact that humans have a sense of freedom to choose. For sir Isaiah Berlin, this is the distinctive characteristic between humans and non-humans. Berlin states:

The central assumption of common thought and speech seems to me to be that freedom is the principal characteristic that distinguishes man from all that is non-human. That there are degrees of freedom, degrees constituted by the

\footnotetext{
${ }^{8}$ Ibid.

${ }^{9}$ P. f. Strawson, op. cit. 23
} 
absence of obstacles to the exercise of choice, the choice being regarded as not itself determined by antecedent conditions, at least not as being wholly so determined. It may be that common sense is mistaken in this matter, or in others; but the onus of refutation lies on those who disagree. ${ }^{10}$

Thus, if the optimists disagree about this common sense assumptions, then they need to prove it. They need to prove that, besides being obscure, it is indeed false that there can be a free choice in the sense in which Isaiah Berlin speaks of it. Clearly there cannot be any freedom to choose if the choice is causally determined by antecedent conditions. However, Strawson centralized human attitudes as sufficient to dismiss the dilemma of freedom.

The optimist's style of over-intellectualizing the fact is that of a characteristically incomplete empiricism, a one-eyed utilitarianism. He seeks to find an adequate basis for certain social practices in calculated sequences, and loses sight (perhaps wishes to lose sight) of human attitudes of which these practices are, in part, the expression. The pessimist does not lose sight of these attitudes themselves which fills the gap in the optimist account. Because of this he thinks the gap can be filled only if some general metaphysical proposition is repeatedly verified, verified in all cases where it is appropriate to attribute moral responsibility. This proposition he finds it difficult to state coherently and with intelligible relevance as its determinist contradictory. Even when a formula has been found (contra-causal freedom or something of the kind) there still seems to remain a gap between its applicability in particular cases and its supposed moral consequences. ${ }^{11}$

This makes Strawson's reconciliatory program apparently simple. It is clear that Strawson's program is that of moderation of the intellectual theorizing and a deemphasis on the metaphysical backing of the libertarian doctrines. But the moderation does not seem to solve the fundamental conflict involving the contradiction between the causal and non-causal paradigms of opponents.

\section{CONCLUSION}

Strawson believes that "If we sufficiently, that is radically, modify the view of the optimist, his view is the right one.' ${ }^{12}$ This clearly shows that Strawson rejects the libertarian's account of contra-causal or non-causal freedom. And he thinks the optimist is right in so far as the question of consequences of moral attitudes involves regulation of behavior. For Strawson, it is the efficacy of moral practices that really counts in its justification. But for him this efficacyis itself grounded in the very nature of human existence. Therefore, it does not require any external or universally general thesis of determinism. Strawson thinks that the determinist is right in so far as his claim rests on the regulative aspect of his doctrine, but wrong in so far as he appeals to an empirically un-verifiable thesis of universal determinism. The universality of deterministic doctrine has no use to justify the regulative function of

\footnotetext{
${ }^{10}$ Isaiah Berlin, 'From Hope and Fear, Set Free', in Concepts and Categories, ed. Henry Hardy (Hogarth Press, London, 1978) 190.

${ }^{11}$ P.F. Strawson, Freedom and Resentment, op. cit. 24

${ }^{12}$ Ibid. ,25.
} 
moral practices. This, as it appears, seems to involve a Kantian solution of the problem in a modified sense.

However, Strawson seems to apply Kantian impossibility of knowledge beyond experience to the determinist doctrine rather than the libertarian one. Whole of Strawsonian thesis or schema focuses on the empirical-moral account of determinism rather than libertarianism. Despite rejection of determinism as irrelevant in explaining interpersonal attitudes, he draws heavily on its empirical content. He states:

It is far from wrong to emphasize the efficacy of all those practices which express or manifest our moral attitudes; in regulating behavior in ways desirable; or to add that when certain of our belief about the efficacy of some of their practices turn out to be false, then we may have good reasons for dropping or modifying those practices. ${ }^{14}$

This shows that Strawson himself has a utilitarian conception of reason, for which he blames the optimist. It would not be a good reason for Strawson to question the regulative aspect of morality. But many serious philosophers have questioned the regulative theoryof punishment. It involves a controversial view of justice in terms of absence of real responsibility. If one practice modifies another practice, or for that matter, regulates it, the question of justification of the act of punishment, on part of the person inflicting the wounds, still arises.

Consequently, Strawsonian theme of interpersonal attitudes seems to ignore the problem of justification of punishment. It is no good reason to argue, in a circular manner, that deterministic morality regulates human attitudes and is itself an expression of those attitudes. Therefore, a universal approach towards explanation of human attitudes is seriously required. ${ }^{15}$ This would be an issue for my next paper on this problem.

\footnotetext{
${ }^{13}$ Kant, as is well known, offered a solution to the problem of relation of knowledge with experience. He pointed out the regulative function of all metaphysical beliefs, especially moral beliefs. For Kant, beliefs in Freedom and responsibility are explainable through practical reasoning in that our practices are regulated by such beliefs, and without them, it would be impossible to have social inter-action. Without supposing freedom in an un-caused sense no one can be considered really responsible. But the noumenal or extra-phenomenal justification of these beliefs through theoretical reason is impossible. This means that for Kant the doctrine of freedom has a regulative function. It shapes the moral practices rather than explaining them in a metaphysical framework of theoretical reasoning.

${ }^{14}$ P.F Strawson" "Freedom and Resentment", op. cit. 25.

${ }^{15}$ Strawson thinks that human consciousness has grown considerably. Objective scientific study of variety of manifestations of human attitudes in historical and anthropological contexts shows this. However, this variety of forms of attitudes complicates our generalization in morality that is confined to a particular culture. But then Strawson thinks that the existence of variety is no obstacle to the acknowledgement of common moral sentiment involved in them. For Strawson, it provides grounds to reconcile pessimists and optimists in that the moral sentiment in general reflects the network of variable human attitudes without the existence of which there cannot be any intelligible system of human relations.
} 


\section{SELECTED BIBLIOGRAPHY}

1. Berlin, Isaiah. 'From Hope and Fear, Set Free.' In Concepts and Categories, edited by Henry Hardy Hogarth Press, London, 1978.

2. Double, Richard. The Non-Reality of Free Will, Oxford: Oxford University Press, 1991.

3. Inwagen, Peter van. An Essay on Free Will, Oxford: Oxford University Press, 1983.

4. Mill, John Stuart. “An Examination of Sir William Hamilton's Philosophy.” In Classic Philosophical Questions, edited by J.A Gould, Prentice Hall , 2006, first published 1971.

5. Thiry, Paul Henry Baron. d' Holbach, "Determinism." In Freedom: Its History, Nature and Varieties, edited by R.E. Dewey and J.A Gould, New York, Macmillan, 1970. 